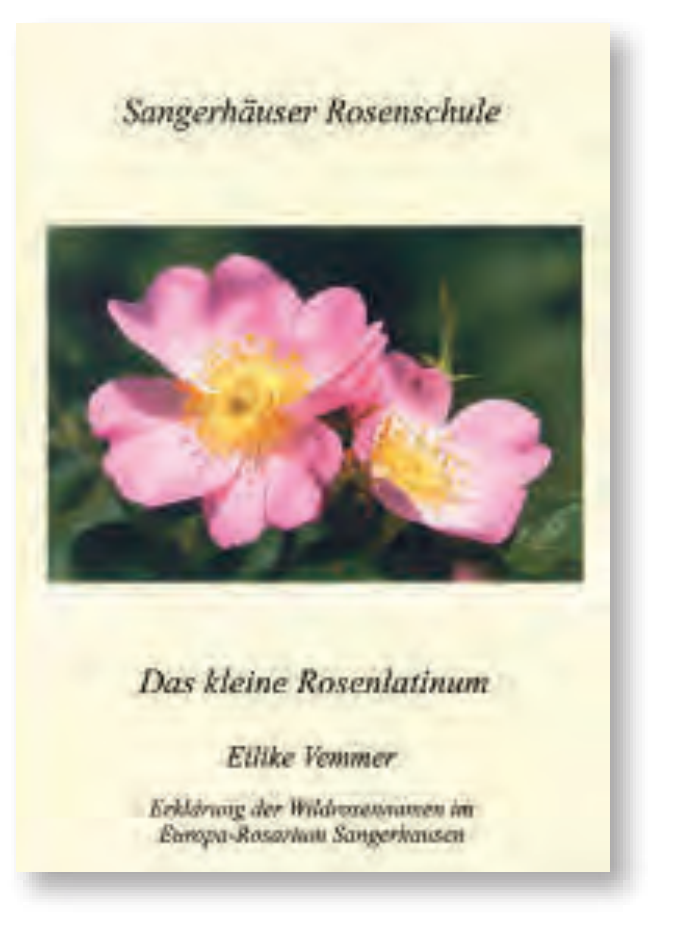

Eilike Vemmer

\section{Das kleine Rosenlatinum. Erklärung der Wildrosennamen im Europa-Rosarium Sangerhausen.}

Förderverein Freunde des Rosariums Sangerhausen e.V, Sangerhausen, 2013, erschienen in der Reihe Sangerhäuser Rosenschule; $10 €$ Bestellungen über den Förderverein Freunde des Rosariums Sangerhausen e.V., Steinberger Weg 3, 06526 Sangerhausen Tel. 03464/572522

E-Mail: nordlandrose@web.de
„Was ich schon immer wissen wollte: Wie haben unsere Botaniker die botanischen und lateinischen Bezeichnungen unserer Wildrosenarten gefunden und welcher Hintergrund verbirgt sich hinter dem botanischen Artnamen?"

Die bekannte Rosenspezialistin EILIKe Vemmer hat jetzt in der Schriftenreihe "Sangerhäuser Rosenschule" mit dem Heft "Das kleine Rosenlatinum“ diese Lücke geschlossen. Von Rosa abetiana, der tannenartigen Rose, bis zu Rosa x zalana, einer Rose benannt nach ihrem Fundort Zala, westlich des Plattensees, führt uns die Verfasserin durch die große Vielfalt der bekannten Wildrosenarten.

Die Einteilung der aufgeführten Wildrosen nach dem System des Botanikers ReHder ist gleichermaßen ein wichtiger Hinweis für interessierte Laien, Studenten, Auszubildende, Gartenbauingenieure und Baumschuler, die sich in die Systematik der Gattung Rosa einarbeiten möchten.

Für wissenschaftlich bewanderte Leser ist die Rubrik mit der Erklärung der abgekürzten Autorennamen eine wichtige Fundgrube. Sie ist unentbehrlich, wenn sich der Leser mit der Vielzahl der synonymen Artnamen in der Gattung Rosa auseinander setzen muss.

Die ausgesuchten Farbfotos der Wildrosenarten vermitteln die Vielfalt und Schönheit einiger der genannten Wildrosen.

Ich freue mich, dass es der Autorin, die für ihre gewissenhaften Recherchen bekannt ist, gelungen ist, mit diesem wichtigen Nachschlagebändchen eine vorhandene Lücke in unserer Rosenbibliothek zu schließen.

Klaus-Jürgen Strobel 